\title{
Welcome to volume 7 of Melanoma Management
}

\author{
Caitlin Killen* \\ ${ }^{1}$ Future Science Group, Unitec House, 2 Albert PI, Finchley, London N3 1QB, UK \\ *Author for correspondence: c.killen@future-science.com
}

First draft submitted: 20 February 2020; Accepted for publication: 20 February 2020; Published online: 1 May 2020

Welcome to the first issue of volume 7 of Melanoma Management. I would like to take this opportunity to wish all our readers a happy new year from all of us here at Future Medicine!

In this Foreword I will be reflecting on 2019 from the perspective of the journal, discussing some of our fantastic content and highlighting some interesting journal stats.

\section{Readership \& author demographics}

In 2019, the majority of our readers came from North America (48\%), joint second were Asia and Europe, both sharing $18 \%$ of the readership (Figure 1). We are delighted that the journal continues to reach audiences worldwide, as well as achieving an increase in readership of over $50 \%$ this year.

Most of our contributing authors came from North America (55\%), with Europe following (26\%) and Australasia in third (16\%; Figure 2). We are thrilled to work with authors from all over the globe and are keen to increase the diversity of our contributors in 2020 .

\section{Content highlights of 2019}

Our most read piece of 2019 was a research article by Wei et al. entitled 'Hypophysitis induced by immune checkpoint inhibitors in a Scottish melanoma population' [1]. In this work the authors demonstrated a high rate of hypophysitis in Scottish melanoma patients receiving ipilimumab and suggested that greater awareness must be brought to adverse events resulting from immune checkpoint inhibitor use.

The second most read article was a short communication from Perez et al. entitled 'Observational study of talimogene laherparepvec use for melanoma in clinical practice in the United States (COSMUS-1)' [2]. Talimogene laherparepvec is the first oncolytic viral therapy approved by the US FDA, and this communication demonstrated that it was well tolerated and revealed clinical utility in melanoma patients.

In 2019 we also published our special focus issue on the multidisciplinary approach to regionally and oligometastatic melanoma. This six-article issue covered a range of topics, including systemic treatments and therapeutic considerations concerning metastatic melanoma. The most read article from this issue was a review from Sun et al. entitled 'The emergence of neoadjuvant therapy in advanced melanoma' [3]. This review examined immunotherapy and targeted therapies in the neoadjuvant setting.

\section{Social media}

Melanoma Management is active on social media and encourages our readers to follow us on twitter (@fsgmmt) in order to keep themselves up to date with our latest content. We discuss the latest news and developments involving melanoma as well as our newly published articles. Twitter allows us to engage with our readers and experts in the field alike.

\section{Conclusion}

Our readers are pivotal to the success of Melanoma Management and we are always keen to receive feedback to ensure the journal is the highest quality possible. Please do not hesitate to get in contact with any suggestions that you may have. We welcome a wide range of unsolicited article types, so please contact us with any article proposals. 

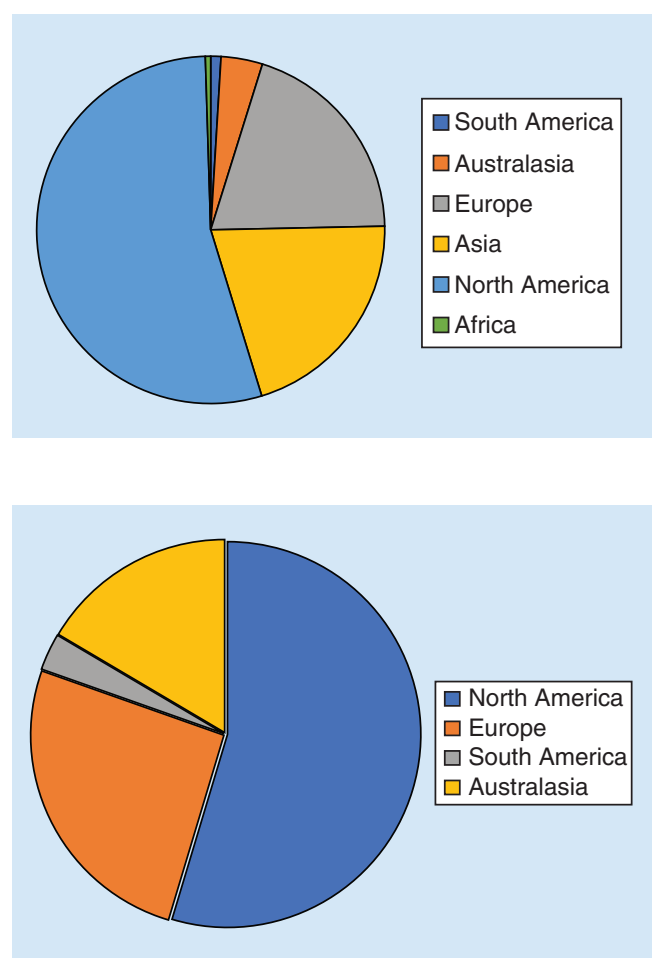

Figure 1. Readership demographics by continent for Melanoma Management in 2019.

Figure 2. Author demographics by continent for Melanoma Management in 2019.

I would finally like to thank our authors, reviewers and editorial board for their hard work and continued support. 2019 has been an excellent year for Melanoma Management and I hope to build on this success and see continued development of the journal in 2020.

Financial \& competing interests disclosure

C Killen is an employee of Future Medicine Ltd. The author has no other relevant affiliations or financial involvement with any organization or entity with a financial interest in or financial conflict with the subject matter or materials discussed in the manuscript apart from those disclosed.

No writing assistance was utilized in the production of this manuscript.

\section{References}

1. Wei KZ, Baxter M, Casasola R. Hypophysitis induced by immune checkpoint inhibitors in a Scottish melanoma population. Melanoma Manag. 6(1), MMT13 (2019).

2. Perez MC, Zager JS, Amatruda $\mathrm{T}$ et al. Observational study of talimogene laherparepvec use for melanoma in clinical practice in the United States (COSMUS-1). Melanoma Manag. 6(2), MMT19 (2019).

3. Sun J, Kirichenko DA, Zager JS, Eroglu Z. The emergence of neoadjuvant therapy in advanced melanoma. Melanoma Manag. 6(3), MMT27 (2019). 